\title{
A primeira etapa do proceso de depuración de mestres e mestras de primeiro ensino na provincia de Lugo: agosto-novembro de $1936^{1}$
}

\author{
The first phase of purge of primary teachers in the province of Lugo: \\ August-November 1936
}

\author{
Rodrigo ALVARADO IGLESIAS \\ Licenciado en Historia \\ Máster en Profesorado de Educación Secundaria Obrigatoria e Bacharelato, \\ Formación Profesional e Ensino de Linguas \\ Máster en Investigación en Educación, Diversidade Cultural e Desenvolvemento Comunitario
}

\begin{abstract}
RESUMO: No estudo que se presenta a continuación abordamos a represión da que foron obxecto os mestres e as mestras de primeiro ensino da provincia de Lugo a partir do estoupido da guerra civil, en xullo do 1936. Concretamente, centrámonos na represión levada a cabo por vía administrativa, é dicir, en forma de depuracións laborais. No que atinxe ao marco temporal, focalizamos a nosa atención na primeira fase da depuración, que se estende dende o inicio do conflito bélico até novembro do 1936, momento en que comezan a funcionar as comisións depuradoras. Dende o punto de vista metodolóxico efectuamos unha aproximación cuantitativa, pero tamén unha aproximación cualitativa analizando os aspectos máis significativos que conformaron o proceso. A maiores, incluímos os nomes daquelas mestras e mestres que sufriron esta primeira acometida represora na provincia de Lugo, porque consideramos que os exercicios de memoria complementan a investigación histórica.
\end{abstract}

PALABRAS CHAVE: ensino primario, mestres e mestras, guerra civil, represión, depuracións.

ABSTRACT: In the study presented below we address the repression suffered by the primary teachers of the province of Lugo from the beginning of the civil war in July 1936. Specifically, we focus on the repression carried out in the form of labor purges. The time frame coincides with the first phase of the purge, which extends from the beginning of the war until November 1936, when it was created the purge commissions. In terms of methodology we conducted a quantitative approach, but, also a qualitative approach analyzing the most significant aspects of the process. Finally we include the names of the teachers who suffered this first purge in the province of Lugo, because we believe that memory exercises complement historical research.

KEY WORDS: primary education, teachers, civil war, repression, purges.

\footnotetext{
${ }^{1}$ A investigación da que procede este traballo foi realizada durante o curso 2013-2014 baixo a dirección do profesor Vicente Peña Saavedra, no marco do Máster de Investigación en Educación, Diversidade Cultural e Desenvolvemento Comunitario. Constitúe unha aproximación inicial á temática da depuración do maxisterio de primeiro ensino na provincia de Lugo que pensamos continuar en futuros proxectos.
} 


\section{A modo de introdución}

Son numerosos os estudos que se levan feito por toda a xeografía do Estado español acerca do proceso de depuración que sufriron os mestres e mestras de primeiro ensino despois do comezo da guerra civil e tras a posterior consolidación do Estado franquista. $\mathrm{Na}$ década dos 80 do pasado século comezaron a aparecer as primeiras investigacións da man de autores como Wenceslao Álvarez ${ }^{2}$ ou Javier $\mathrm{Crespo}^{3}$, que indagaron sobre a depuración de ensinantes de primaria nas provincias de León e Burgos respectivamente. Na década dos 90 incrementouse considerablemente a produción científica arredor deste eido. Destacan os traballos realizados por Maitane Ostolaza ${ }^{4}$, Josep González e Salomó Marqués ${ }^{5}$, Ramón Jiménez ${ }^{6}$ ou Juan Manuel Fernández e María del Carmen Agulló7. A primeira década do novo século trouxo consigo unha mellora cualitativa da que foi a principal responsable Sara Ramos, quen realizou na súa tese de doutoramento unha fonda reflexión sobre todos os aspectos en liza no proceso de depuración acometido en Castela-A Manchå

Dende o punto de vista historiográfico é salientable a evolución no tratamento do obxecto de investigación: dende o simple reconto de sancións e docentes depurados dos primeiros momentos até os enfoques cualitativos propios dos traballos máis modernos, marcados polo emprego dos expedientes de depuración como fonte. Non obstante, a característica fundamental radica en que a maior parte das investigacións se circunscribe ao ámbito provincial ou rexional, de modo que aínda a día de hoxe faltan propostas de carácter global. Salvada excepción é o estudo de Francisco Morente, La Escuela y el Estado Nuevo. La depuración del magisterio nacional (1936-1943)', no que a través da análise do acontecido nunha mostra de 14 provincias trata de achegar conclusións para o conxunto do Estado. Máis recentemente Sara Ramos emprendeu algunhas iniciativas baseadas na comparación dos resultados da purga nas distintas provincias e rexións partindo de estudos xa feitos ${ }^{10}$.

En Galicia prevalecen tamén os traballos de corte provincial. Xosé Manuel Cid realizou unha aproximación á depuración do maxisterio en Ourense recollida en Educación e ideoloxía en Ourense na II República: organización e acción socio-educativa do

\footnotetext{
2 Wenceslao Álvarez Oblanca, La represión de postguerra en León. Depuración en la enseñanza, 1936-1943 (Madrid: Santiago García Editor, 1986).

${ }^{3}$ Jesús Crespo Redondo, Purga de maestros en la guerra civil. La depuración del magisterio de la provincia de Burgos (Valladolid: Ámbito, 1987)

${ }^{4}$ Maitane Ostolaza Esnal, El garrote de la depuración. Maestros vascos en la guerra civil y el primer franquismo (1936-1945) (Donostia: Ibaeta Pedagogía, 1996).

${ }^{5}$ Josep González-Agapito e Salomó Marqués i Sureda, La repressió del profesorat a Catalunya sota el Franquisme (1939-1943) (Barcelona: Institut d'Estudis Catalans, 1996).

${ }^{6}$ Ramón Jiménez Madrid, La depuración de maestros en Murcia (1939-1942) (Murcia: Universidad de Murcia, 1997).

7 Juan Manuel Fernández Soria e María del Carmen Agulló Díaz, Maestros valencianos bajo el franquismo (Valencia: Institut Alfons el Magnánim, 1999).

${ }^{8}$ Sara Ramos Zamora, La depuración del magisterio de primera enseñanza en Castilla-La Mancha (1936-1945) (Madrid: Universidad Complutense de Madrid, 2005).

${ }^{9}$ Francisco Morente Valero, La escuela y el Estado Nuevo. La depuración del Magisterio Nacional (1936-1943) (Valladolid: Ámbito, 1997).

${ }^{10}$ Sara Ramos Zamora, "Control y represión. Estudio comparado de los resultados de la depuración del magisterio primario en España”, Revista Complutense de Educación no 1 (2006): 169-182.
} 
Maxisterio ${ }^{11}$. Pola súa banda, os traballos de Anxo Serafín Porto, O maxisterio pontevedrés na Il República, Guerra Civile Franquismo ${ }^{12}$ e Mestras e mestres pontevedreses depurados polo franquismo ${ }^{13}$, dan conta do que supuxo a represión dos docentes pontevedreses. María Jesús Souto, na súa monumental obra La represión franquista en la provincia de Lugo $^{14}$, dedica un apartado a estudar a purga da que foron obxecto os traballadores do ensino lucenses, mais trátase dun enfoque principalmente cuantitativo que nos dá unha visión ampla no plano estatístico, pero deixa moito por facer no plano cualitativo.

\section{As fontes}

As fontes empregadas para a realización deste estudo foron:

- Gaceta de Madrid. Foi o medio oficial de comunicación en vixencia durante a etapa republicana. A través del accedemos ás medidas reformistas que os gobernos republicanos progresistas impulsaron en materia educativa. Foi consultado en rede na páxina web do Boletín Oficial do Estado.

- Boletín Oficial da Xunta de Defensa Nacional (de agora en diante BXDM). Foi o órgano oficial de comunicación do bando nacional a partir da constitución da Xunta de Defensa Nacional. Contén as normas que rexeron o proceso de depuración na súa primeira fase. Consultado en rede.

- Boletín Oficial do Estado (BOE).Substituíu o BXDN a partir de outubro do 1936. Tamén se utilizou principalmente para a análise de medidas legais en relación coa educación e co proceso de depuración do maxisterio. Foi consultado en rede.

- Boletín Oficial da Provincia de Lugo (BOP). Nel puidemos acceder ás circulares do gobernador civil e ás listaxes de depurados correspondentes á primeira etapa. A maiores, contén ordes e outras disposicións legais que foron de interese para este traballo. Foi revisado no Arquivo Histórico Provincial de Lugo (AHPL).

- Expedientes de depuración de mestres e mestras de primeiro ensino da provincia de Lugo. Comezaron a confeccionarse a partir de novembro do 1936, é dicir, co comezo da segunda fase do proceso de depuración. Porén, son útiles tamén para o estudo da primeira etapa porque moita da documentación xerada durante os intres iniciais da purga foi anexada a estes expedientes. Foron consultados no Arquivo Xeral da Administración (AXA), situado en Alcalá de Henares.

- Documentación do Goberno Civil, documentación das Sección Administrativa de Primeiro Ensino e da Inspección de Primeiro Ensino. Sobre todo, correspondencia e documentos de traballo interno que foron de utilidade para completar algúns aspectos da presente investigación. Accedeuse a ela no AHPL e no Arquivo Histórico da Universidade de Santiago de Compostela (AHUS).

\footnotetext{
${ }^{11}$ Xosé Manuel Cid Fernández, Educación e ideoloxía en Ourense na II República: organización e acción socioeducativa do Maxisterio (Santiago de Compostela: Andavira, 2010).

${ }_{12}$ Anxo Serafín Porto Ucha, O maxisterio pontevedrés na Segunda República, Guerra Civil e Franquismo (Ponteareas: Alén Miño, 2003).

${ }^{13}$ Anxo Serafín Porto Ucha, Mestras e mestres pontevedreses depurados polo franquismo. Primeiras accións represivas e estudo por concellos no sur da provincia (1936-1942) (Ponteareas: Alén Miño, 2008).

${ }_{14}^{14}$ María Jesús Souto Blanco, La represión franquista en la provincia de Lugo (1936-1940) (Sada: Edicións do Castro, 2008).
} 
- Documentación da Reitoría da Universidade de Santiago de Compostela. Fundamentalmente correspondencia, resolucións da xunta de decanos, listaxes de depurados enviadas dende o Goberno Civil e informes sobre mestres e mestras. Foi revisada no AHUS.

\section{A lóxica violenta dos sublevados: represión e xenocidio}

Xa dende os primeiros días da guerra os militares sublevados impulsaron unha intensa campaña de terror para asegurar o control dos territorios que ían quedando baixo 0 seu dominio, mais tamén para eliminar fisicamente a toda aquela persoa que fora percibida como opositora. No proxecto de "novo Estado" que tiñan en mente non cabían as ideas progresistas e mesmo revolucionarias que levaban agromando en España dende finais do século XIX e que callaran nalgúns proxectos durante a etapa republicana. Por esta razón, había que aniquilar ou, cando menos, privar de liberdade a quen as impulsaba e as defendía. Baixo as gadoupas asasinas do exército, de falanxistas, de requetés e de individuos adeptos á "causa" caeron mortas milleiros e milleiros de persoas e outras moitas foron encarceradas en penais e en campos de concentración.

A forte represión desatada nas zonas dominadas polo bando nacional non foi de carácter reactivo, senón preventivo. Recorreuse de forma sistemática ao asasinato e a outras mediadas de coerción para asentar as bases do novo poder e para paralizar 0 inimigo mediante o terror, non como reacción diante do que acontecía na fronte de guerra. Isto explica a violencia despregada en territorios de retagarda que, como Galicia, caeran rapidamente en mans dos nacionais sen que houbese enfrontamento bélico ${ }^{15}$. $E$ é que 0 grande obxectivo da guerra para os rebeldes non pasaba exclusivamente pola derrota do réxime republicano no campo de batalla, senón que había que:

eliminarlo de raíz, desarticular sus bases sociales de apoyo e impedir toda futura reorganización. Y eso se conseguía no sólo ocupando el poder, sino haciendo desaparecer todo tipo de organización, institución, ideas y personas que fueran proclives o defensoras de este régimen ${ }^{16}$.

O recurso á violencia era un elemento inherente aos plans dos militares sublevados. No mes de maio do ano 1936, durante o proceso de preparación do golpe de Estado que finalmente se materializaría en xullo, o xeneral Emilio Mola, un dos principais organizadores, fixo circular entre os mandos castrenses implicados na trama golpista a coñecida Instrución reservada número 1 , en que explicitamente se facía alusión á contundencia que debía acompañar o pronunciamento:

Se tendrá en cuenta que la acción ha de ser en extremo violenta, para reducir lo antes posible al enemigo, que es fuerte y bien organizado. Desde luego, serán encarcelados todos los directivos de los partidos políticos, sociedades o sindicatos no afectos al movimiento, aplicándose castigos ejemplares a dichos individuos para estrangular los movimientos de rebeldía o huelgas ${ }^{17}$.

\footnotetext{
${ }^{15}$ Mirta Núñez Díaz-Balart, "El porqué y el para qué de la represión”, en La gran represión. Los años de plomo del franquismo, coord. Mirta Núñez Díaz-Balart (Barcelona: Flor del Viento Ediciones, 2009), 31.

${ }^{16}$ Jesús de Juana López e Julio Prada Rodríguez, "Conclusiones", en Lo que han hecho en Galicia. Violencia, represión y exilio (1936-1939), coords. Jesús de Juana López e Julio Prada Rodríguez (Barcelona: Crítica, 2006), 293.

${ }^{17}$ Fragmento da Instrucción reservada no 1 extraído do traballo de Manuel Álvaro Dueñas, "«Por derecho de fundación»: la legitimación de la represión franquista”, en La gran represión. Los años de plomo del franquismo, coord. Núñez, 64.
} 
Esta instrución constitúe unha auténtica declaración de principios que, ademais de dar conta do cariz premeditado da represión, tamén nos amosa a quen se tiña que castigar. Era prioritario reprimir os elementos da sociedade civil contrarios aos ideais reaccionarios que eles defendían e nos que se apoiaba o sistema republicano (partidos políticos, sociedades e sindicatos). Había que neutralizar de forma "en extremo violenta" os resortes de articulación da cidadanía nun contexto democrático como o creado durante a República, para así rachar con calquera posible intento de resistencia e crear uns sólidos alicerces nos que asentar o novo sistema.

Aínda que o exército foi o principal protagonista tanto no impulso como na materialización da onda de exterminio e represión non foi o único actor. Os diferentes repertorios de violencia non só entraron en funcionamento de arriba cara a abaixo, senón que en abondosas ocasións comezaron por iniciativa das bases, dos cidadáns de a pé. Foron moitas as persoas que se sumaron á tarefa de limpeza ordenada desde as altas esferas militares, uns apertando o gatillo de forma directa, outros delatando e outros simplemente consentindo. Segundo 0 xuízo de Claudio Hernández "parece evidente que una parte de la población no solo aceptó que se castigara a los vencidos, sino que compartió los fines de la represión y la implementó en la medida de sus posibilidades"18. Xa que logo, tamén unha parte considerable da responsabilidade sobre 0 acontecido recae na sociedade civil como colaboradora e, moitas veces, como impulsora e perpetradora da barbarie.

As dimensións e as características que tivo o terror despregado durante e despois da guerra civil fan que unha corrente relativamente recente dentro da historiografía española defina 0 acontecido como xenocidio. A violencia aniquiladora impulsada contra persoas de tendencia progresista, xa foran ideoloxicamente próximos ao republicanismo, ao nacionalismo, ao comunismo ou ao anarquismo, parece responder máis ben ao intento por rematar cun grupo social que, aínda que diferente no ideolóxico e no socioeconómico, tiña como nexo de unión a súa oposición ao ideario reaccionario que encarnaba o bando nacional.

Un dos autores que ten defendido con máis decisión esta tese nos últimos anos é Antonio Míguez, quen diferencia entre represión e xenocidio, ao tempo que apunta que 0 carácter xenocida da violencia posta en práctica polos sublevados estaba presente dende a preparación do golpe de Estado:

os obxectivos da sublevación militar eran fundamentalmente de tipo xenocida. Dentro do que é a violencia, e máis especificamente a lóxica represiva, a práctica xenocida ten uns trazos específicos, 0 máis sinalado de todos é a súa intencionalidade exterminadora. Esta intencionalidade vai acompañada de segregar a sociedade sobre a que se actúa en dous grupos incomunicados entre si, o dos verdugos e 0 das vítimas. Mentres que a represión pretende asegurar o exercicio do poder para os que reprimen, a violencia xenocida aspira a reconfigurar a sociedade pola vía de negarlle a unha parte da mesma 0 dereito á propia existencia ${ }^{19}$.

En efecto, a violencia impulsada polos militares rebeldes tratou, por unha banda, de eliminar unha parte da poboación que era percibida como inimiga e que non tiña cabida na nova orde e, pola outra, de reducir á marxinación a todas aquelas persoas que simpatizaran co anterior sistema ou que non se apegaran aos principios e valores do novo réxime.

${ }^{18}$ Claudio Hernández Burgos, Franquismo a ras de suelo: zonas grises, apoyos sociales y actitudes durante la dictadura (1936-1975) (Granada: Universidad de Granada: 2013), 120.

${ }^{19}$ Antonio Míguez Macho, Xenocidio e represión franquista en Galicia (Santiago de Compostela: Lóstrego, 2009), 80. 


\section{Diferentes repertorios violentos: a represión administrativa dos funcionarios da Administración pública}

Para comprender axeitadamente como o poder nacente se valeu da violencia para forxar as bases do sistema político e social que pretendía implantar é preciso dar cabida a unha definición ampla do concepto, como a achegada por Julio Aróstegui. Para este historiador violencia é: "toda resolución o intento de resolución, por medios no consensuados de una situación de conflicto entre partes enfrentadas, lo que comporta esencialmente una acción de imposición, que puede efectuarse, o no, con presencia manifiesta de fuerza física"20.

O poder do bando nacional, primeiro, e o Estado franquista, despois, fixeron uso doutros repertorios violentos a maiores do emprego da forza física e da aniquilación do inimigo. As ferramentas represoras coas que se tratou de infundir terror na cidadanía e de despexar o camiño para a imposición do seu ideal de Estado foron variadas. Unha delas foi a depuración de funcionarios da Administración pública.

A depuración do persoal que traballaba para a Administración foi definida por Josefina Cuesta como un "proceso preventivo y punitivo que constituye una estrategia más de control, de selección del personal funcionario y de eliminación de elementos considerados nocivos para la sociedad que se pretende construir, mediante la humillación y el miedo"21. Afectou á totalidade de corpos de traballadores públicos e respondeu a tres obxectivos fundamentais. En primeiro lugar, permitiu unha purga ideolóxica e política dentro da Administración do Estado. En segundo termo, deixou tras de si moitos postos vacantes que serían aproveitados para recompensar a aqueles que participaron dunha ou doutra maneira na conflagración bélica a carón do bando nacional. Por último, privar de traballo as persoas desafectas co incipiente réxime, e polo tanto, dos medios de obtención de ingresos económicos, foi unha ferramenta sumamente útil para botar por terra a súa influencia social e para relegalas a unha condición de marxinación desde a que acometer calquera acción de oposición era impensable ${ }^{22}$.

\section{0 colectivo docente: un branco prioritario da represión}

Un dos colectivos que máis cedo e con máis ímpeto sufriu o rigor da depuración laboral e ideolóxica foi o dos traballadores e traballadoras do ensino. Dende o mesmo mes de agosto do ano 1936 foron sometidos a control milleiros de docentes en todos os estratos do sistema educativo: universidades, escolas normais, institutos de secundaria, escolas de primaria etc. Aínda que a maioría non foron sancionados, a manobra serviu para construír un clima de temor xeneralizado e para crear un corpo condescendente cos valores e maneiras de actuar do poder militar ${ }^{23}$.

\footnotetext{
20 Julio Aróstegui Sánchez, "Violencia, sociedad y política: la definición de violencia", Ayer, noำ 13 (1994): 30.

${ }^{21}$ Josefina Cuesta Bustillo, "Introducción", en dir. Josefina Cuesta Busitllo La depuración de funcionarios bajo la dictadura franquista, (Madrid: Fundación Francisco Largo Caballero, 2009), 15.

${ }_{22}$ Francisco Moreno, "La represión en la posguerra. Otras formas de represión", en coord. Santos Juliá, 361.

${ }^{23}$ Sara Ramos Zamora, "Maestros y maestras de primera enseñanza bajo la dictadura franquista. Depuración y represión", en dir. Cuesta.
} 
Ademais de estaren suxeitos ao sistema de depuración creado expresamente para a purga no ámbito educativo, tamén se viron afectados por outras leis de carácter represor: a Lei de responsabilidades políticas de 1939, a Lei de represión da masonaría e do comunismo de 1940 ou a Causa Xeral de 1941. Isto conduce a Sara Ramos a sentenciar que: "el paso por toda esta arquitectura represora nos lleva a pensar que el sector docente fue uno de los más castigados del conjunto de funcionarios del Estado"24.

A razón de que a maquinaria depuradora se cebara tan ferozmente co mundo do ensino reside en que o sistema educativo estaba chamado a cumprir unha importante función na construción do poder reaccionario que defendían os sublevados. Debía servir como axente de socialización básico que transmitise os principios, valores, ideas, actitudes e crenzas necesarios para lexitimar e para converter en duradeiro o réxime nacente. Paralelamente, os dirixentes nacionais, en concordancia co pensamento máis puramente tradicionalista e conservador, rexeitaban profundamente as mudanzas acometidas polos gobernos republicanos progresistas no eido da educación.

Polo transcendental papel no que atinxe á socialización dende a máis tenra infancia, pero tamén porque era o de maior implantación no conxunto do territorio estatal e aquel ao que podían acceder todos os estamentos sociais, o ensino primario foi o elo do sistema educativo en que máis incidencia tivo a purga ${ }^{25}$. Deste modo e sen perdermos de vista, por un lado, o obxectivo de botar por terra todos e cantos avances se conseguiran durante a etapa republicana en materia de educación primaria e, polo outro, para contribuír a forxar unhas bases cidadás ancoradas no catolicismo, tradicionalismo e inmobilismo que precisaba o novo réxime:

Era necesaria unha purga. Había que castigar ao maxisterio, non soamente polo que fixera anteriormente, senón como prevención para o futuro. De aí a represión dende os primeiros días do alzamento militar. Había que construír unha nova escola: a escola do "Estado Novo" ${ }^{26}$

É importante poñer de manifesto que aínda que nos centramos na represión vía administrativa da que foron obxecto os mestres e as mestras de primeiro ensino da provincia de Lugo durante os primeiros meses da guerra civil, cómpre non esquecer que houbo abondosos casos en Galicia de docentes que sufriron a barbarie asasina a mans dos militares rebeldes ou de falanxistas, como corroboran os traballos realizados por Antón Costa ${ }^{27}$.

\section{As etapas do proceso de depuración}

A depuración do colectivo docente non foi un proceso perfectamente uniforme. Pola contra, pasou por distintas fases que se foron sucedendo de xeito paralelo á definición e desenvolvemento das novas institucións de goberno.

\footnotetext{
24 Ibid. 54.

${ }^{25}$ Cómpre lembrar que no AXA consérvanse 52.074 expedientes de depuración referidos a mestres e mestras de primeiro ensino.

${ }^{26}$ Porto Ucha, Mestras e mestres pontevedreses depurados polo franquismo, 48.

${ }^{27}$ Antón Costa Rico, "Os ensinantes galegos e 0 36. Os mortos e os exiliados", en VVAA, A /l República e a Guerra Civil. Actas do II Congreso da Memoria (Ferrol: Embora, 2006), 487-500
} 
Segundo Sara Ramos ${ }^{28}$ pódense distinguir tres etapas, cada unha delas determinada polas características emanadas do aparato legal que regulaba como se había de levar a cabo a purga, principalmente: quen eran os responsables de recadar a información sobre os docentes, quen tiña competencias para ditaminar resolucións, cales eran as actuacións susceptibles de ser sancionadas e que tipos de sancións se consideraban.

- Primeira etapa. Comprendida entre os meses de agosto e novembro do ano 1936. Durante este tempo a responsabilidade da depurar recaeu en autoridades locais e rexionais como alcaldes, reitores ou gobernadores civís.

- Segunda etapa. Abrangue dende novembro de 1936 até a constitución do Ministerio de Educación Nacional en xaneiro de 1938. No mes de novembro do ano 1936 promulgouse - Decreto número $66^{29}$ que estableceu a creación das comisións provinciais de depuración, mudando substancialmente o funcionamento do proceso. ${ }^{30}$

- Terceira etapa. A creación do Ministerio de Educación Nacional ${ }^{31}$, enmarcada dentro da reorganización e reformulación do poder que o bando nacional realizou a principios do 1938, inaugurou unha nova fase caracterizada pola constitución da Oficina TécnicoAdministrativa de Depuración en marzo dese ano ${ }^{32}$, e en agosto do 1939, xa rematada a guerra, da Comisión Superior Ditaminadora ${ }^{33}$. Ambas as dúas entidades foron as encargadas de rematar o labor de depuración dos docentes de primeiro ensino.

Porén, os ecos desta represión administrativa prolongáronse no tempo, pois xa dende 1942, coa creación do Xulgado Superior de Revisións, comezou un proceso de revisión das resolucións que durou até a década dos sesenta: no transcurso da lectura dos expedientes de depuración que levamos a cabo no AXA demos cunha sentenza de revisión ditada para un mestre lucense con data do 16 de decembro de $1963^{34}$.

\section{Marco legal da primeira fase do proceso de depuración}

A Xunta de Defensa Nacional, o primeiro órgano de goberno do bando nacional, promulgou dúas normas a través das cales quedou definido o marco legal da primeira fase do proceso de depuración: a Orde do 19 de agosto de 1936 e a Circular do 16 de setembro de 1936.

\section{Orde do 19 de agosto de 1936}

A Orde do 19 de agosto ${ }^{35}$ introduciu as primeiras fórmulas represivas referidas ao maxisterio de primaria, de tal forma que constituíu o paso inicial dado polos mandos

\footnotetext{
${ }^{28}$ Sara Ramos Zamora, La represión del Magisterio: Castilla- La Mancha, 1936-1945(Ciudad Real: Almud, 2006), 35-44. ${ }^{29}$ Decreto do 8 de novembro de 1936 (BOE 11-XI-1936).

${ }^{30}$ Establecéronse catro comisións: a Comisión "A", encargada da depuración do ámbito universitario; a Comisión "B", orientada ao persoal das escolas de enxeñeiros e de arquitectos; a Comisión "C", con competencias sobre institutos, escolas normais, de comercio, de artes e oficios, de traballo, inspectores de primeiro ensino e a Comisión "D", dedicada ao maxisterio de primaria. A principal misión das comisión provinciais era a de reunir información sobre o persoal da súa incumbencia, efectuar propostas de resolución (sancionadoras ou non sancionadoras) e elevalas á Comisión de Cultura.

${ }^{31}$ Lei do 30 de xaneiro de 1938 (BOE 31-I-1938).

${ }^{32}$ Orde do 11 de marzo de 1938 (BOE 19-III-1938).

${ }^{33}$ Orde do 18 de marzo de 1938 (BOE 23-III-1938).

${ }^{34}$ Expediente de depuración do mestre Antonio Crespo Fernández (AXA, Sección de Educación, caixa 32/13204 (3)).

${ }^{35}$ Orde do 19 de agosto do 1936 (BXDN21-VIII-1936).
} 
sublevados para elaboraren un marco normativo que legalizase a purga que se ía emprender neste nivel do sistema educativo.

A través do seu segundo e sexto artigo legalizouse o mecanismo primixenio de control e represión dos mestres nos territorios controlados polos militares rebeldes. 0 artigo segundo establecía unha medida de control da que se fixeron responsables aos alcaldes das comisións xestoras municipais:

Poner en conocimiento del Rectorado respectivo toda manifestación de debilidad u orientación diferente a la sana y patriótica actitud del Ejército y pueblo español, que siente a España grande y única, desligada de conceptos antiespañolistas que sólo conducen a la barbarie. ${ }^{36}$

Pola súa parte, o artigo sexto incluía xa medidas sancionadoras dirixidas contra aqueles mestres que non cumprisen cos preceptos ideolóxicos dos sublevados:

Antes del día 30 del corriente mes los Alcaldes informarán al Rectorado del Distrito Universitario respecto a si la conducta observada por los Maestros propietarios o interinos que desempeñaban las escuelas en las localidades respectivas ha sido la conveniente en orden a las finalidades de esta disposición, o si por el contrario han mostrado aquellos en el ejercicio de su cargo ideario perturbador de las conciencias infantiles así en el aspecto patrítico como en el moral. En este último caso, los Rectores ordenarán con toda urgencia la sustitución de dichos Maestros [...]". ${ }^{37}$

Esta disposición deixaba nas mans de autoridades locais e rexionais, alcaldes e reitores, o labor represivo: os primeiros eran os encargados da confección dos informes e os segundos de ditaminaren a resolución correspondente. Polo demais, non dispoñía ningún tipo de gradación nas sancións, simplemente indicaba a substitución do mestre por parte do reitor cando o seu perfil ideolóxico e as súas actuacións non se axustasen aos valores e ideas do novo sistema.

\section{Circular do 16 de setembro de 1936}

A Orde do 19 de agosto veríase complementada pola Circular do 16 de setembro ${ }^{38}$, a cal introduciu unha gradación nas sancións en función do contido do informe que as autoridades elaborasen:

Primero. Los maestros cuyos informes sean totalmente desfavorables por sus actuaciones anteriores, no sólo en su aspecto perturbador de las conciencias infantiles, sino por su conducta amoral 0 antipatriótica serán inmediatamente suspendidos de empleo y sueldo y se publicará en los Boletines Oficiales de la provincia respectiva.

Segundo. Maestros de conducta no bien definida en los informes de los Alcaldes o que por organizaciones o personalidades solventes fueron de actuación dudosa. Los Rectores consultarán a cuantos organismos o personalidades crean que pueden aclarar las dudas. Si de los datos recibidos merecieran ser incluidos en el apartado primero, quedarán suspensos de empleo y sueldo. Si no resultasen acreedores de esta medida radical, pero por su indiferencia en cultivar las inteligencias, conducta discutible, abandono de sus servicios, etcétera, apreciaren los Rectores que merecen alguna sanción de menor importancia, los suspenderán de uno a tres meses de empleo y sueldo o hasta seis meses de empleo y medio sueldo.

Tercero. Maestros cuyos informes dados por los Alcaldes fueran favorables y no hubiesen llegado a los Rectorados otros desfavorables emitidos por organizaciones de solvencia moral y patriótica, quedan ratificados en sus cargos. ${ }^{39}$

\footnotetext{
${ }^{36} \mathrm{Ibid}$

${ }^{37}$ Ibid.

${ }^{38}$ Circular do 16 de setembro de 1936 (BXDN 19-IX-1936).

${ }^{39} \mathrm{lbid}$.
} 
Xa que logo, as posibles resolucións quedaron tipificadas en tres categorías: suspensión de emprego e soldo de duración indeterminada para os mestres cos informes máis "graves"; suspensión de emprego e soldo de duración determinada para os casos intermedios e ratificación no posto se 0 docente conta cun informe totalmente favorable.

Ademais, a Circular do 16 de setembro tamén esboza cales son as condutas que deben ser punidas. Os elementos pedagóxicos ou didácticos quedan nun segundo plano, ocupando a ideoloxía e os valores dos docentes os motivos centrais das sancións: "[...] no sólo en su aspecto perturbador de las conciencias infantiles, sino por su conducta amoral o antipatriótica". ${ }^{40}$

\section{A primeira fase da depuración na provincia de Lugo: o destacado papel do gobernador civil}

Como se desprende da análise realizada no apartado anterior, as disposicións lexislativas outorgaban aos reitores dos distintos distritos universitarios a competencia na imposición de sancións aos mestres e mestras de primeiro ensino, logo de consultaren os informes remitidos polos alcaldes. No entanto,, na práctica, foron en moitos casos os gobernadores civís os que acapararon un papel principal. Así aconteceu na provincia de Lugo, cuxo gobernador civil, Ramón Bermúdez de Castro, foi o máximo responsable do ditame de destitucións, suspensións de emprego e soldo e traslados de escola dentro da provincia ao longo dos meses de agosto e setembro do 1936.

Bermúdez de Castro, nomeado gobernador a comezos de agosto polo xeneral xefe da Oitava División Militar ${ }^{41}$, á que pertencía Galicia, pronto comezou a actuar no ámbito educativo. Unha das primeiras iniciativas que tomou foi a disolución dos consellos locais e do consello provincial de primeiro ensino e a constitución duns novos. Os escollidos para conformaren os novos consellos foron o alcalde de cada municipio, como presidente, un crego, un mestre, un pai e unha nai. No caso do consello provincial o presidente sería 0 propio gobernador civil ${ }^{42}$. Esta decisión pódese entender como unha medida inicial orientada a establecer mecanismos de control sobre a multitude de escolas que había espalladas pola provincia, ao tempo que se constituía unha valiosa ferramenta para abrir unha canle de información sobre o proceder e a tendencia ideolóxica dos ensinantes.

O ideario de Bermúdez de Castro, que transloce a través das circulares que foi publicando no Boletín Oficial da Provincia durante o tempo que estivo no cargo, está en concordancia co pensamento conservador e tradicionalista dos sublevados. En relación coa educación escolar o gobernador considera que ten que pivotar sobre dous principios básicos e irrenunciables: a relixión e a patria. Neste sentido, entende como labor fundamental dos docentes inculcar aos nenos e nenas os valores relixiosos da moral católica, non só por razóns espirituais, senón tamén como medio para garantir a súa lealdade e entrega incondicional ao Estado:

\footnotetext{
${ }^{40} \mathrm{lbid}$.

${ }^{41}$ Bermúdez de Castro preséntase ante a poboación de Lugo como gobernador civil nunha circular do 9 de agosto de 1936 (BOP 11-VIII-1936).

${ }^{42}$ No $B O P$ do 28 de agosto e no $B O P$ do 31 de agosto figura a relación das persoas que compoñen os novos consellos de primeiro ensino, tanto os municipais como o provincial.
} 
Ante todo y sobre todo, será idea primordial que guiará la labor docente del profesorado, el que la formación espiritual de la niñez esté siempre de acuerdo con las más puras normas de la moral cristiana, única que puede imponer un Estado que aspire a contar en un mañana no lejano con ciudadanos que sean útiles para la Patria, teniendo la abnegación precisa para servirla y para amarla. ${ }^{43}$

Alén da patria, a relixión converteuse no segundo grande elemento de recorrencia retórica por parte do bando nacional. A escola debía xogar un papel transcendental na creación dunha conciencia patriótica nos máis novos e os mestres serían os encargados de espertala dende a máis tenra infancia:

De igual manera se cuidará con el mayor celo y atención preferentemente a la formación patriótica de la niñez, enseñándole a conocer a España, haciéndole sentir y comprender la idea de la Patria y sensibilizándosela en la forma adecuada a ser percibida por sus tiernas y simplistas inteligencias; materia ésta perfectamente apta para que corazones que sientan con celo de apostolado la labor augusta de la enseñanza pongan a contribución todo su amor, toda su inteligencia y toda su alma para conseguir encender en las dulces almas de los niños el fervor sagrado a una Patria que, como la nuestra, tiene una historia tan gloriosa que por precisión tiene que deslumbrar los espíritus prontos a la admiración de todo lo noble y generoso. ${ }^{44}$

Co obxectivo de materializar na práctica escolar diaria as súas directrices ideolóxicas, o gobernador estaba convencido de que era preciso impulsar actuacións dirixidas ao colectivo de ensinantes. Había que asegurar a súa correcta moral relixiosa e o seu ideario patriótico e con tal intención promulgou unha circular, a comezos de setembro, en que estableceu unha serie de medidas que tiñan por función controlar o acceso dos mestres interinos aos postos vacantes:

Teniendo en cuenta que han de reanudarse las tareas escolares en esta provincia, es necesario que los Maestros que hayan de regentar Escuelas, siquiera sea interinamente, vengan rodeados de las máximas garantías para el Estado, no sólo por su aptitud y capacidad, sino también, y de condición primordial y especialísima en el Magisterio, por una moral cristiana a toda prueba, acendrado patriotismo y dotes inequívocas de honrada ciudadanía; en uso de las facultades que me están conferidas, acuerdo:

Primero. Declarar nulas, y sin ningún valor y efecto las listas de aspirantes a interinidades de esta provincia.

Segundo. Quienes deseen regentar Escuela interinamente, presentarán sus solicitudes en la Sección Administrativa hasta el 15 del presente mes [...]. Cada instancia vendrá acompañada del informe detallado del Sr. Alcalde y Sr. Cura Párroco, donde resida el solicitante, que versará, precisamente, sobre los requisitos establecidos en el preámbulo de la presente orden, quedando sin curso las que carezcan de dicho informe. ${ }^{45}$

Non obstante, Bermúdez de Castro xa comezara a súa particular cruzada contra 0 maxisterio de primeiro ensino da provincia de Lugo a finais de agosto: a primeira listaxe de mestres sancionados por decisión gobernativa leva sinatura do 26 de agosto ${ }^{46}$. A esta seguírona outras catro asinadas con datas de $5,15,19$ e 21 de setembro. ${ }^{47}$

As sancións con que se castigou aos mestres mediante estas resolucións estiveron en concordancia co marco legal emanado da Xunta de Defensa Nacional. Nun primeiro momento (resolucións do 26 de agosto e do 5 de setembro), de acordo coa Orde do 19 de agosto, aplicouse unha separación do posto de traballo en forma de destitución.

\footnotetext{
${ }^{43}$ Circular do 9 de setembro de 1936 (BOP 11-IX-1936).

${ }^{44} \mathrm{lbid}$.

${ }^{45}$ Circular de 2 de setembro de 1936 (BOP 5-IX-1936).

${ }^{46}$ BOP 28-VIII-1936.

${ }^{47}$ Publicadas respectivamente nos BOP do 7, 15, 19 e 21 de setembro.
} 
Seguidamente (resolucións do 15 de setembro ${ }^{48}$, do 19 e 21 dese mesmo mes), facendo uso da graduación nas sancións que recollía a Circular do 16 de setembro, aplicáronse traslados entre escolas da mesma provincia e suspensións de emprego e soldo de duración determinada.

O celo con que se empregou Bermúdez de Castro fixo que o reitor da Universidade de Santiago de Compostela, en quen recaía dende o punto de vista legal a depuración, apenas tivese que intervir ditando medidas sancionadoras na provincia de Lugo. De feito, na documentación oficial para esta fase só se recollen dúas sancións a mestres de primaria promulgadas polo reitor. ${ }^{49}$

Foi unha actuación rápida e contundente. En menos dun mes publicouse a práctica totalidade das resolucións de depuración na provincia correspondentes a esta primeira etapa. O feito de que se actuase con tanta rapidez concorda á perfección coa lóxica represora empregada polo bando rebelde. Era necesario aniquilar o inimigo con prontitude no campo de batalla, pero tamén na retagarda e, ademais, era imprescindible, para asegurar o poder e asentar os alicerces do novo réxime, rachar con todos os mecanismos de influencia social que puidese ostentar. A escola e os mestres eran un destes mecanismos e, por iso, sufriron dende o momento mesmo do comezo da guerra toda a atención represiva por parte das autoridades leais ao bando nacional, como neste caso do gobernador civil da provincia de Lugo, Ramón Bermúdez de Castro.

\section{Os informes: un elemento clave}

Unha ferramenta fundamental, na que se apoiaron tanto os gobernadores civís como os reitores para procederen ao ditame de resolucións sancionadoras, foron os informes elaborados sobre os mestres e mestras por parte das autoridades locais. Convertéronse nun instrumento básico no proceso represivo dende o comezo do conflito armado e institucionalizáronse como tal unha vez xa asentado o Estado franquista.

A través da súa análise podemos coñecer o perfil dos mestres sancionados e, paralelamente, podemos facer un achegamento a que tipo de autoridades e personalidades tiñan lexitimidade para emitilos. Para o caso da provincia de Lugo non se conservan os informes que puido ter recibido Bermúdez de Castro entre a documentación do Goberno civil existente no AHPL. Non obstante, si se conservan algúns referidos a mestres de Lugo e ao período temporal que nos ocupa entre a documentación da Reitoría da Universidade de Santiago de Compostela no AHUS, así como nos expedientes de depuración do maxisterio custodiados no AXA. As reflexións que realizamos a continuación están baseadas neles.

Os informes procedían do ámbito local e eran remitidos a instancias superiores con competencias no ámbito educativo. Con todo, durante esta primeira fase de depuración non se seguiu un criterio uniforme na súa canalización: algúns foron remitidos ás Seccións Administrativas, que parece ser que foi nun primeiro momento o organismo encargado de

\footnotetext{
${ }^{48}$ Esta resolución, a pesar de asinarse uns días antes da entrada en vigor das disposicións contidas na Circular da Xunta de Defensa Nacional de 16 de setembro, xa inclúe catro suspensións de emprego e soldo de duración determinada.

${ }^{49}$ BOP 16-XII-1936.
} 
recibilos e de transmitirllos ao Goberno Civil eá Reitoría; outros foron remitidos directamente ao Goberno Civil; e outros chegaron sen pasar por ningún tipo de intermediario á Reitoría da Universidade de Santiago de Compostela.

As autoridades que os asinaban eran persoas que contaban coa confianza plena dos poderes afectos ao bando rebelde e que axiña se converteron no poder do novo réxime. A maior parte están asinados polos alcaldes que, como marcaban as normas, eran os responsables de facilitar a información sobre os docentes que traballaban no seu municipio. Porén, tamén son frecuentes os informes asinados por membros da Falanxe e por autoridades militares.

As acusacións que transcenden da análise dos informes que manexamos son principalmente de tipo político e ideolóxico, o que encaixa coa valoración de Francisco Morente desta primeira etapa como un movemento cuxo obxectivo principal foi: "separar del servicio a aquellos maestros que, de una forma u otra, se habían significado durante la etapa republicana por ideas 0 actuaciones que las nuevas autoridades consideraban contrarias a los principios que inspiraban su movimiento"50. Algúns exemplos destas acusacións son:

Y para que V.E. pueda ver claramente quienes son los Maestros de referencia no tiene inconveniente la Alcaldía en añadir a los informes emitidos que el Maestro de Santalla, D. Eustasio F. Ferreira inculcaba varios días a la semana a los niños la doctrina de que "Ahora no se necesitaban guardias civiles, ni ejército, porque desde que hay República todo era orden y paz, ni tampoco curas ni iglesias porque para rezar nada se necesitaba de todo eso que era una invención". ${ }^{51}[\ldots]$

En un local de su casa, del mismo edificio donde está la escuela, tuvo bastante tiempo instalado uen Centro Socialista, con cuyo elemento simpatizaba, al extremo de ser suscriptora permanente del "Pueblo Gallego", periódico que fomentó la revolución en Galicia. ${ }^{52}[. .$.

Lo primero que se le ocurrió fue hacer propaganda socialista con todas sus consecuencias: que debía socializarse la propiedad, que la tierra debía ser de quien la trabaja, que los colonos no debían respetar los propietarios, que la Religión era un mito y que debían agruparse en una sociedad socialista para que los defendiese de las garras de los propietarios. ${ }^{53}[. .$.

Se dedicó a la propaganda comunista acompañando al ex diputado Villamil, revolucionario de acción, recientemente fusilado, por diversas parroquias de dicho distrito y por si esto mereciera el cese en el desempeño del cargo de Maestro, por considerar que su actuación ha de ser perjudicial a los fines del actual movimiento glorioso Militar. ${ }^{54}[$... $]$

Fue y es Presidente de una "Sociedad Obrera de Trabajadores de la Tierra de Germade", afecta a la U.G.T., fundada por él y el Maestro de Casabella, D. Robustiano de Castro (...). Dicha Sociedad tenía carácter meramente revolucionario, y servía para ir cazando la juventud y dar conferencias de propaganda avanzada y nociva, causando un daño inmenso en varias parroquias del municipio. ${ }^{55}[. .$.

Tengo el honor de informar: que no practica la Religión Católica, en absoluto; que es de filiación política de carácter socialista y marxista, partidaria del Frente Popular a cuyo favor trabajó en el orden particular, siendo opuesta por tanto al movimiento del Ejército. ${ }^{56}$

\footnotetext{
${ }^{50}$ Morente Valero, La escuela y el Estado Nuevo. La depuración del Magisterio Nacional (1936-1943), 184.

${ }^{51}$ Comunicacións e informes sobre os mestres depurados na provincia de Lugo, 1936-1938, AHUS, Ensino primario, caixa 176 e 177

52 Ibid

${ }^{53} \mathrm{Ibid}$

${ }^{54} \mathrm{Ibid}$

${ }^{55}$ Expediente de depuración do mestre Jesús Baamonde Ramudo (AXA, Sección de Educación, caixa32/12723 (1)).

${ }^{56}$ Expediente de depuración da mestra Manuela Moyer Guardiola (AXA, Sección de Educación, caixa 32/12723 (9)).
} 
A tendencia ideolóxica e a participación en partidos políticos ou sindicatos foron os dous elementos máis perseguidos nos primeiros meses polo novo poder. Iso foi o que sucedeu tamén na depuración do maxisterio. A multitude de informes que se xeraron dende 0 ámbito local conformaron a base en que se apoiaron os encargados de promulgaren as resolucións durante a fase inicial da purga. Das súas decisións resultaron sancionados nos primeiros meses da guerra civil un elevado número de mestres e mestras.

\section{Unha breve análise dos datos}

Segundo os datos recollidos das fontes oficiais (BOP) durante a primeira fase da depuración do maxisterio de primeiro ensino na provincia de Lugo foron sancionados un total de 184 mestres e mestras. A meirande parte, 182, por orde do gobernador civil, mentres que tan só 2 por decisión da Reitoría da Universidade de Santiago de Compostela. Así e todo, o gobernador civil ditou 186 resolucións, xa que se deu o caso de 4 mestres que recibiron dúas sancións. ${ }^{57}$

No tocante ao tipo de sancións, podemos falar de tres grandes grupos. En primeiro lugar, a destitución; en segundo lugar, o traslado de escola; e en terceiro lugar, a suspensión de emprego e/ou soldo. Porén, na práctica, o abano de sancións foi máis amplo, pois houbo mestres aos que se lles impuxo o traslado e a maiores algún tipo de suspensión de emprego e soldo. É necesario especificar que as dúas sancións ditadas pola Reitoría levaron a denominación de suspensión indefinida de emprego e soldo ${ }^{58}$, o cal na práctica funcionaba como unha destitución.

Cronoloxicamente as sancións gobernativas concéntranse (atendendo ao momento en que foron asinadas, non cando se publicaron no BOP) nos meses de agosto e setembro. No primeiro, predominan as destitucións, mentres que no segundo xa se produce a combinación de destitucións con outro tipo de castigos. As dúas promulgadas pola Reitoría tiveron lugar no mes de novembro.

Cadro 1. Número e porcentaxe de docentes sancionados atendendo ao mes en que se ditaron as resolución e ás sancións impostas. Elaboración propia a partir dos datos recollidos no BOP de Lugo.

\begin{tabular}{|l|c|c|c|c|c|c|}
\hline & Agosto & Setembro & Outubro & Novembro & Total & $\%$ \\
\hline D & 82 & 34 & - & - & 116 & 63 \\
\hline SI & - & - & - & 2 & 2 & 1,1 \\
\hline T & - & 49 & - & - & 49 & 26,6 \\
\hline TSES & - & 2 & - & - & 2 & 1,1 \\
\hline TSS & - & 2 & - & - & 2 & 1,1 \\
\hline SES & - & 7 & - & - & 7 & 3,8 \\
\hline SS & - & 6 & - & - & 6 & 3,3 \\
\hline Total & 82 & 100 & - & 2 & 184 & 100 \\
\hline
\end{tabular}

\footnotetext{
Lenda

\begin{tabular}{|cl|}
\hline D & Destitución \\
\hline SI & Suspensión indefinida de emprego e soldo \\
\hline T & Traslado \\
\hline TSSE & Traslado con suspensión de emprego e soldo \\
\hline
\end{tabular}
}

TSS Traslado con suspensión de soldo

SES Suspensión de emprego e soldo

SS Suspensión de soldo

\footnotetext{
${ }^{57}$ Os catro mestres aos que nos referimos foron sancionados co traslado, ao que se lle engadiu a suspensión de emprego e soldo por un tempo determinado.

58 "Comunicación do Reitorado", Comunicacións e informes sobre os mestres depurados na provincia de Lugo,1936-1938, AHUS, Ensino primario, caixas 176 e 177.
} 
De maneira clara a sanción máis recorrente foi a destitución dos ensinantes do seu posto de traballo, pois representa máis do $60 \%$ dos casos, seguida moi de lonxe co traslado a outra escola, que pasa do $25 \%$. Esta elevada porcentaxe no uso da sanción máis severa danos mostra do ímpeto represor con que se empregou Bermúdez de Castro.

Pola súa banda, se prestamos atención á distribución por sexos, apréciase unha porcentaxe moito maior de mestres sancionados ca de mestras: $19 \%$ mulleres e $81 \%$ homes.

No que atinxe á distribución territorial, observamos que en todos os partidos xudiciais hai docentes sancionados, sen que sexan as diferenzas sumamente salientables. Estaecuanimidade na distribución territorial das sancións parece indicar que foi unha prioridade actuar en todos os puntos da provincia. Ao mesmo tempo, puidemos comprobar como se castigou mesmo a mestres que non rexentaban escola no curso que estaba a piques de comezar.

Cadro 2. Distribución territorial das sancións. Elaboración propia a partir dos datos
\begin{tabular}{|l|c|} 
recollidos no BOP de Lugo. \\
Partido xudicial
\end{tabular}
\begin{tabular}{|l|c|} 
Becerreá & Mestres sancionados \\
\hline Chantada & 18 \\
\hline A Fonsagrada & 19 \\
\hline Lugo & 13 \\
\hline Mondoñedo & 20 \\
\hline Monforte & 13 \\
\hline Quiroga & 19 \\
\hline Ribadeo & 11 \\
\hline Sarria & 22 \\
Vilalba & 12 \\
Viveiro & 21 \\
Non rexentaba escola & 11 \\
\hline
\end{tabular}

Se tomamos en consideración os números dados por Antón Costa, quen expón que en 1935 desempeñaban o seu labor na provincia de Lugo un total de 1491 mestres $^{59}$, resulta que aproximadamente un $12,3 \%$ dos docentes de primeiro ensino foi sancionado nesta primeira acometida represiva. Cifra que, aínda que non acada o $25 \%$ que referencia Porto Ucha para Pontevedra ${ }^{60}$, dá mostra da categórica actuación das novas autoridades fronte a todos aqueles docentes que percibían como unha potencial ameaza. Este elevado índice de sancións nos primeiros meses da contenda provocou, xunto coa masiva incorporación de mestres a filas, moitas dificultades para comezar o novo curso académico con normalidade. Entre a documentación revisada no AHUS atópanse moreas de oficios e comunicacións de alcaldes ou veciños de moitos municipios e localidades da provincia que dan conta da imposibilidade de botar a andar o novo curso por falta de ensinante que se faga cargo da escola.

Para rematar este apartado é imprescindible facermos fincapé na provisionalidade dos datos cuantitativos. Demos con indicios que sinalan que o número de mestres e mestras depurados e punidos durante esta primeira etapa foi máis elevado que o que nós ofrecemos, xa que o BOP de Lugo non recolle a actuación de autoridades (caso do comandante militar de Ribadeo), que tamén emitiron sancións como indica algunha fonte á que tivemos acceso:

\footnotetext{
${ }^{59}$ Antón Costa Rico, Escolas e Mestres. A educación en Galicia: da Restauración á segunda República (Santiago de Compostela: Consellería de Presidencia e Administración Pública, 1989), 383.

${ }^{60}$ Porto Ucha, Mestras e mestres pontevedreses depurados polo franquismo, 58-59
} 
Maestra Nacional № 7333 del escalafón general a V.S.I. respetuosamente expone: Que habiendo sido destituida por el Comandante militar de la plaza de Ribadeo, de la escuela de niñas que cerca de once años desempeñó en Villaframil. ${ }^{61}$

\section{Conclusións}

Da valoración dos datos e do discorrer do proceso da primeira fase de depuración do maxisterio de ensino primario na provincia de Lugo, podemos establecer as seguintes conclusións:

A primeira fase do proceso de depuración de mestres e mestras de primaria tivo unha duración moi limitada no tempo, pois case todas as resolucións sancionadoras se concentraron nos meses de agosto e de setembro. A pesar disto, tivo unha incidencia moi elevada na provincia, como vimos de ver, dado que máis do $12 \%$ dos docentes de primeiro ensino sufriu algún tipo de medida punitiva antes da posta en funcionamento das comisións de depuración.

Unha personalidade transcendental na posta en marcha da purga en Lugo a partir de agosto do 1936 foi o gobernador civil, Ramón Bermúdez de Castro. Aínda que as normas emanadas da Xunta Técnica de Estado deixaban en mans dos reitores o labor depurador, en moitas provincias, como en Lugo, foi o gobernador civil quen a levou a termo. Que fose Bermúdez de Castro o principal impulsor da represión do maxisterio concorda perfectamente cos postulados ideolóxicos que defendía nas súas circulares: a escola debía responder aos máis puros valores tradicionais, flanqueados pola relixión católica e pola noción de patria, co que consecuentemente debía estar rexida por aqueles mestres e mestras que non se tiveran significado ideolóxica e politicamente durante a etapa republicana.

Amais do gobernador civil, tamén hai que ter presente a imposición de sancións por parte doutras autoridades como o comandante militar de Ribadeo. Así mesmo, é preciso salientar a achega fundamental na elaboración dos informes de acusación das que paulatinamente se ían converter nas novas caras do poder: os militares leais ao bando sublevado; os alcaldes postos á fronte das comisións xestoras municipais por orde destes militares; os falanxistas; máis tarde o clero etc.

Durante toda esta primeira etapa hai abondosos detalles de improvisación, falla de coordinación e de criterios uniformes de actuación entre as distintas autoridades. Con todo, da actuación do Goberno Civil de Lugo transcende a presenza dunha certa organización represiva: elaboración de listaxes de mestres sancionados que eran enviadas á Reitoría da Universidade de Santiago de Compostela, de informes nos que se detalla concello por concello as sancións impostas etc.

As resolucións ditadas durante estes momentos iniciais foron revisadas polas comisións depuradoras na segunda fase da purga, de maneira que moitas das sancións foron atenuadas. Non obstante, esta contundente maneira de actuar contra os mestres e mestras de primaria supuxo un importante avance do que ía ser a represión no mundo da educación por parte do novo poder. A escola debía servir para transmitir as ideas dos

\footnotetext{
${ }^{61}$ Expediente de depuración da mestra Manuela Moyer Guardiola (AXA, Sección de Educación, caixa 32/12723 (9)).
} 
sublevados (despois vencedores) e para xerar un clima de aceptación e de identificación co "Movimiento Nacional". Por iso, eliminar calquera posible oposición dentro dela foi un obxectivo central dende que os primeiros territorios quedaron baixo a batuta dos nacionais. $O$ feito de que nos informes que se conservan prime resaltar a orientación política e sindical do docente fronte a outras cuestións, como puidera ser a forma de proceder dende o punto de vista pedagóxico, indica que a purga do profesorado era un paso fundamental de cara a converter a escola nun efectivo instrumento de adoutrinamento político e ideolóxico.

En definitiva, a represión laboral e ideolóxica á que foron sometidos mestres e mestras dende os intres iniciais da guerra debe ser entendida dentro do clima xeral de violencia e eliminación do inimigo que impulsaron os militares nacionais, primeiro, e despois o Estado franquista. A construción e consolidación do novo poder levouse a cabo dende o comezo mediante o emprego da violencia física, do asasinato, do encarceramento, pero tamén mediante resortes administrativos disfrazados de legalidade que permitiron estender as medidas represoras a todos os ámbitos da vida institucional e cidadá.

Anexo:

\section{Os nomes}

A continuación, damos conta do nome das mestras e mestres que sufriron algún tipo de sanción durante a primeira etapa do proceso de depuración. Os nomes foron transcritos a partir das fontes oficiais xeradas polas institucións do bando nacional, o cal pode levar canda si a existencia dalgún erro. Igualmente, como xa puxemos de manifesto ao longo do traballo, de seguro que hai ensinantes que foron depurados durante o tempo que abranguemos no noso estudo que non constan nos documentos oficiais e, polo tanto, faltan os seus nomes nas liñas que seguen.

Abramo Dios, Juan; Aguilar Gómez, Eduardo; Aloguín Roig, Santiago; Álvarez Barreiros, Francisco; Álvarez Besteiro, María Encarnación; Álvarez López, José; Álvarez Sánchez, Manuel; Arévalo Simón, José; Arias Sánchez, José; Arranz Ruiz, Julia; Arrojo Suárez, Julia; Bahamonde Ramudo, Jesús; Balboa Caamaño, José; Basanta Lienderrozos, Teresa; Batán, Eduardo; Bermúdez Peñamaría, Justina; Bolaño López, Alejo; Borrego Jiménez, Cándido; Cabanillas Calderón, Cándido; Cadahía Vázquez, Julio; Camarero Vera, Pedro; Cancio Muruais, Primitivo; Canosa Nimo, Manuela; Carballido, Daniel; Carmena Carmena, Antonio; Casabella Santos, María Dolores; Castillo Gómez, Felipe; Castro Carballeira, Robustiano; Ceide Vilar, Emilio; Colubí González, Concepción; Conde Costa, Antonio; Costa Pardo, José; Crespo Fernández, Antonio; Cruces Romero, Jesús; Cruz Lamas, Manuel; Darriba Rodríguez, Emilio; De Castro Penabad, Constantino; De La Vega Alonso, Angel; Devesa Vázquez, María Del Carmen; Díaz García, José; Díaz Gómez, Arsenio; Díaz Ufano Y De Vega, Matías; Enrique Arnau, José; Enríquez Crespo, Elidia; Enríquez Moure, José Ramón; Estadella Herrero, Domingo; Fernández Ferrería, Eustasio; Fernández López, Enrique; Fernández López, Manuel; Fernández Rivas, Efigenia; Fernández Taboada, María Aurora; Fernández Vázquez, Rogelio; Fernández, Daniel; Fernández, José; Ferreiro Ares, Francisco; Ferreiro Doval, José; Figueroa García, Perfecto; Fraga Orosa, Ángel; Franco Carballeira, Francisco; Franco Carballeira, Josefa; 
Gallo Álvarez, Gloria; Gallo Gallo, José María; García Olivares, Juan José; García Sola, Filomena; Gómez Argiz, Evangelina; Gómez Castro, José; Gómez Díaz, Eulogio; González Vázquez, José María; González Vizoso, Vicenta; Goy Porto, Juan; Gueimonde López, José; Gutiérrez Armajach, Julia; Herrero García, Jesús; Labrador Zuil, David; Lafoz López, Luis Angel; Lence Trashorras, Domingo; Lombardía Otero, José; López Blanco, José; López Cabanillas, José; López Cabanillas, María; López Castrillón, Herminio; López Conde, Gregorio; López Franco, Manuel; López García, Benito; López Gonzáles, Aurora; López López, Alfredo; López Pérez, Balbino; López Sánchez, Ángel; López y López, José; Lorenzo Fernández, José Ramón; Margolles De La Vega, César; Martín Redondo, Aureliano; Martínez Crespo, Pablo; Martínez González, Josefa; Martínez Martínez, Antonio; Martínez Monteira, Clemenete; Méndez Sacadas, Antonio; Mirayo López, Angel; Molleda Pardo, Librada; Montero Gómez, Pilar; Mourelle López, Dolores; Murga Clemente, Amador; Muruais Carballosa, Enrique; Nieto Chaín, Gabriela; Nine Fernández, Segundo; Novo Gonzáles, Francisco; Novo Rico, José; Novoa Pérez, Carmen; Orosa González, Leonardo; Ortiz Bautista, Armando; Otero Méndez, Amancio; Pacho Vicente, Felipe Santiago; Paradiñeiro Paradiñeiro, Alfredo; Pardo Y Pardo, Benigno; Pareja Morales, Pedro; Pena Arcajo, José María; Pereira Vilares, Jesús; Pérez López, Antonio; Pérez Pasarín, Benedicto; Pico Blanco, Domingo Antonio; Picón San Miguel, Ticiano; Piedracoba Ación, Antonio; Pin Villares, Isaac; Pinado Rodríguez, Abraham; Portela Maseda, Venancio; Prieto Cosén, Elisa; Prieto Saavedra, Manuel; Pumarega Díaz, Avelino; Quesada Ruiz, Antonio; Quián Pérez, Dolores; Quintela Ferreiro, Antonio; Rayón López, Tomás Carlos; Refojo Freire, Elena; Regueiro Cabanas, Pedro; Rey Santamaría, Juan; Rico Fernández, Vicente; Rivas Reboleiro, Francisco; Rivas Rouco, José; Rodríguez Bodas, Juan Manuel; Rodríguez Cárdenas, Angel Ricart; Rodríguez Rivera, José; Rodríguez Ruíz, Antonio; Rodríguez Vázquez, Josefa; Romero Soneira, Eugenio; Romero Vázquez, Angel Leonardo; Saco López, Camilo; Saco López, Pedro; Sánchez Friol, Emilio; Sánchez García, Juan; Sánchez Iglesias, Concepción; Sanmartín Cornes, Regino; Sanmartín Cornes, Regino; Santamaría Becerra, Antonio; Santos Salvador, Benedicto; Santos Vila, Angel; Sanz García, Gregorio; Serapio Suárez, Luis; Sesma Virto, Isidro; Sierra Méndez, Marina; Silva Díaz, Bautista; Silva Díaz, Daniel; Somoza Pérez, Francisco; Torrón Fole, Manuel; Tourón López, José; Uz Barja, Jesús; Valcárcel Calancha, Guillermo; Valero Navajas, Joaquín; Valls García, Salvador; Varela Quiroga, Antonio; Varela Seijas, Jesús; Vázquez Álvarez, Sebastián; Vázquez Rey, Rosina; Vázquez Sánchez, Elena; Veiga González, Carmen; Velayos Y Pérez Cardenal, Manuel; Verde Barranca, Ricardo; Vidán Torres, Alfonso; Vieitez García, José; Vilares Quintana, Casimiro; Villar Vidueira, Franciso; Villariño Marqués, Atilano; Viña Gómez, Eugenio; Vizoso Vizoso, José; Yebra Huertas, José. 